Tropical Journal of Pharmaceutical Research December 2014; 13 (12): 2083-2090

ISSN: 1596-5996 (print); 1596-9827 (electronic)

(c) Pharmacotherapy Group, Faculty of Pharmacy, University of Benin, Benin City, 300001 Nigeria.

All rights reserved.

Available online at http://www.tjpr.org

Original Research Article

http://dx.doi.org/10.4314/tjpr.v13i12.20

\title{
Artificial Neural Networks and Concentration Residual Augmented Classical Least Squares for the Simultaneous Determination of Diphenhydramine, Benzonatate, Guaifenesin and Phenylephrine in their Quaternary Mixture
}

\author{
Hany W Darwish ${ }^{1,2 *}$, Fadia H Metwally ${ }^{2,3}$, Abdelaziz El Bayoumi ${ }^{2}$, Ahmed A \\ Ashour $^{4}$ \\ ${ }^{1}$ Department of Pharmaceutical Chemistry, College of Pharmacy, King Saud University, PO Box 2457, Riyadh 11451, Saudi \\ Arabia, ${ }^{2}$ Department of Analytical Chemistry, Faculty of Pharmacy, Cairo University, Kasr El - Aini Street, ET 11562, Cairo, \\ Egypt, ${ }^{3}$ Ibn Sina National College for Medical Studies, AIMahjer Road, Jeddah, Saudi Arabia, ${ }^{4}$ Department of Analytical \\ Chemistry, Faculty of Pharmacy, Misr International University, Cairo, Egypt
}

*For correspondence: Email: hdarwish75@yahoo.com; hdarwish@ksu.edu.sa

Received: 15 October 2014

Revised accepted: 12 November 2014

\begin{abstract}
Purpose: To develop two multivariate calibration methods for the simultaneous spectrophotometric determination of a quaternary mixture composed of diphenhydramine $\mathrm{HCl}$, benzonatate, guaifenesin and phenylephrine $\mathrm{HCl}$ in Bronchofree ${ }^{\mathrm{TM}}$ capsules in the ratio of $2.5: 10: 10: 1$, respectively.

Methods: Novel artificial neural networks (ANNs) and concentration residual augmented classical least squares (CRACLS) methods were developed for the quantitative determination of the quaternary mixture. For proper analysis, a four-level, four-factor experimental design was established resulting in a training set of 16 mixtures containing different ratios of the four analytes. A validation set consisting of six mixtures was used to validate the prediction ability of the suggested models.

Results: ANNs and CRACLS methods were successfully applied for the analysis of raw materials and capsules. For ANNs method, \% recovery of diphenhydramine $\mathrm{HCl}$, benzonatate, guaifenesin and phenylephrine $\mathrm{HCl}$ in the capsules was $102.21 \pm 1.34,100.30 \pm 1.17,99.31 \pm 2.00$ and $98.50 \pm 1.27$, respectively. On the other hand, \% recovery of the four analytes by CRACLS was $99.84 \pm 2.22,100.07$ $\pm 0.63,98.37 \pm 1.42$ and $97.99 \pm 0.96$, respectively.

Conclusion: The proposed methods can be applied for the quantitative determination of the four components without interference from excipients, thus obviating the need for preliminary extraction of analytes from the pharmaceutical formulation. The ability of the methods to deconvolute the highly overlapped UV spectra of the four components' mixtures using low-cost and easy-to-handle instruments such as UV spectrophotometer is also an advantage.
\end{abstract}

Keywords: Artificial neural networks, Concentration residual augmented classical least squares, Quaternary mixture, Simultaneous determination

Tropical Journal of Pharmaceutical Research is indexed by Science Citation Index (SciSearch), Scopus, International Pharmaceutical Abstract, Chemical Abstracts, Embase, Index Copernicus, EBSCO, African Index Medicus, JournalSeek, Journal Citation Reports/Science Edition, Directory of Open Access Journals (DOAJ), African Journal Online, Bioline International, Open-J-Gate and Pharmacy Abstracts

\section{INTRODUCTION}

The work introduced in this paper aims to analyze the quaternary mixture composed of diphenhydramine hydrochloride benzonatate (BN), guaifenesin (GU) and phenyl ephrine hydrochloride $(\mathrm{PH})$ in their synthetic mixture as well as in dosage form. Upon extensive literature review, only one recent reported HPLC method [1] is available for the 
simultaneous analysis of this mixture. Therefore, development of simple, accurate, and sensitive methods for the routine analysis of this combination is of invaluable importance. DP [2 (diphenylmethoxy) - N,N - dimethylethylamine hydrochloride] [2] is an effective antihistaminic, and has been used for the treatment of motion sickness and extrapyramidal symptoms, as well as an antitussive.

Recently, it has been used as antiemetic in chemotherapy treatment [3]. DP is a common ingredient of cough and cold preparations and is also used as a hypnotic [4]. BN [4 (Butylamino)benzoic

acid $3,6,9,12,15,18,21,24,27$ - nanooxaoctacos - 1$\mathrm{yl}$ ester $)]$ is an effective antitussive [2] . GU [3-(2 - Methoxyphenoxy) - 1, 2 - propanediol] is reported to reduce the viscosity of sputum and used as an effective expectorant [4]. PH [3 - (2 Methoxyphenoxy) - 1,2 - propanediol] is an alpha - adrenergic sympathomimetic agent which stimulates alpha - adrenergic receptors, producing pronounced vasoconstriction [3]. The combination of the four drugs is used for treating bronchial spasm and as antitussive. The UV absorption spectra of the four drugs display considerable overlap that hinder the application of the conventional spectrophotometry for resolving their spectra. Therefore different chemometric methods, namely; artificial neural networks (ANNs) and concentration residual augmented classical least squares (CRACLS) were applied for the simultaneous analysis of this complex mixture. The choice of these two methods was based on their high quantitative predictive power. The principles and theories of these two models are discussed in the literature [5-11].

\section{EXPERIMENTAL}

\section{Instrumentation}

Schimadzu UV - Visible Spectrophotometer 1601 PC equipped with $1 \mathrm{~cm}$ quartz cells. The bundled software was UVPC personal spectroscopy software version 3.7 (Shimadzu). The wavelength scanning speed was $2800 \mathrm{~nm}$ $\min ^{-1}$. PLS - 1 analysis was carried out by using PLS - Toolbox software version 2.0-PC for use with MATLAB (Version 7, Math Work, Inc).

\section{Materials and reagents}

Pharmaceutical grade of DP, BN, GU and $\mathrm{PH}$ were used and certified to contain $99.90 \%$, $99.87 \%, 99.15 \%$ and $99.30 \%$ respectively. Potassium hydroxide and methanol used were analytical grade. Bronchofree capsules (batch no. 811062, Adwia Pharmaceuticals and Chemical Industries Co, Cairo, Egypt) were used. Each capsule had a labelled content of 25 mg DP, $100 \mathrm{mg} \mathrm{BN}, 100 \mathrm{mg} \mathrm{GU}$ and $10 \mathrm{mg} \mathrm{PH.}$

\section{Standard and working solutions}

Stock standard solutions of DP, BN, GU and PH were prepared separately by dissolving $125 \mathrm{mg}$ of DP, $250 \mathrm{mg} \mathrm{BN}, 250 \mathrm{mg} \mathrm{GU}$ and $125 \mathrm{mg} \mathrm{PH}$ in $100 \mathrm{~mL}$ distilled water. DP was dissolved in least amount of methanol and complete to volume with water. Corresponding working solutions were prepared by transferring accurately $12.5,25,25$ and $6 \mathrm{~mL}$ from DP, BN, GU and $\mathrm{PH}$ stock standard solutions separately in $250 \mathrm{~mL}$ measuring flasks and the volume made up to mark with distilled water.

\section{Calibration}

\section{Construction of the training set}

Multilevel multifactor design [12] was used for the construction of the calibration set. A calibration set of 16 samples was prepared for calibration. A four level four factor calibration design was used in which 4, 4.5, 5.5 and $6 \mathrm{~mL}$ aliquots of the four working solutions were combined and $1 \mathrm{~mL}$ of $0.05 \mathrm{~N} \mathrm{KOH}$ was added then volume completed to $25 \mathrm{~mL}$ with distilled water. The UV absorption spectra were recorded over the range 200-350 $\mathrm{nm}$ against solvent blank contains $30 \mu \mathrm{g} \mathrm{mL}^{-1} \mathrm{GU}$ treated exactly as the samples. The data points of the spectra were collected at every $1 \mathrm{~nm}$. Final concentration ranges were $10-15 \mu \mathrm{g} \mathrm{mL}{ }^{-1}$ for DP, 40-60 $\mathrm{g} \mathrm{mL}^{-1}$ for BN and GU, $4.8-7.2 \mu \mathrm{g}$ $\mathrm{mL}^{-1}$ for $\mathrm{PH}$.

\section{Pre-processing the data}

Reject the regions from 200 - $215 \mathrm{~nm}$ and above $340 \mathrm{~nm}$. For ANN method: The absorbance matrix was factor analyzed before introducing into the network using principal component analysis (PCA) and ANN model was run. The scores of principal components (PCs) were used to convert other data matrices into corresponding PCs

\section{Validation}

Validation set of 6 samples was prepared to check the performance of the ANN and CRACLS models.

\section{Application to pharmaceutical preparation}

Weigh accurately liquid content of 10 capsules and stirred for $5 \mathrm{~min}$. with $20 \mathrm{~mL}$ methanol. 
Complete to $250 \mathrm{~mL}$ with distilled water. Transfer accurately $5 \mathrm{~mL}$ of this solution to $100-\mathrm{mL}$ measuring flask and complete to volume with distilled water. The final concentratons were 50 $\mu \mathrm{g} \mathrm{mL}{ }^{-1}$ for DP, $200 \mu \mathrm{g} \mathrm{mL}^{-1}$ for both BN and $\mathrm{GU}, 20 \mu \mathrm{g} \mathrm{mL}^{-1}$ for PH. Take 5, 6, 7 and 7.5 from this solution and and add $1 \mathrm{~mL}$ of $0.05 \mathrm{~N} \mathrm{KOH}$ then complete volume to $25 \mathrm{~mL}$ with distilled water. The general procedures described under calibration were followed and the concentration of each compound was calculated.

\section{RESULTS}

\section{Optimization of spectral measurements}

The chemical structures of DP, BN, GU and PH are shown in Fig 1. Fig 2 shows the UV absorption spectra of $\mathrm{DP}, \mathrm{BN}, \mathrm{GU}$ and $\mathrm{PH}$ at their nominal concentrations in capsules. As these figures show there is a clear overlapping between them especially $\mathrm{DP}, \mathrm{GU}$ and $\mathrm{PH}$; the spectral overlapping of the drugs prevents resolution of the mixtures by direct spectrophotometric measurements. Thus, the univariate analysis cannot be applied to resolve their mixtures. The optimum conditions for quantitative estimation of considered compounds were established via a number of preliminary experiments. The medium is rendered alkaline to produce hyperchromic shift for $\mathrm{PH}$ [13] by addition of $1 \mathrm{~mL}$ of $0.05 \mathrm{~N} \mathrm{KOH}$ just before measurements to prevent hydrolysis of $\mathrm{BN}$ that may occurred in alkaline medium [14]. Mixtures were measured against solvent blank contain 30 $\mu \mathrm{g} \mathrm{mL} \mathrm{L}^{-1}$ of $\mathrm{GU}$ to decrease absorbance of overall mixture sample. A calibration set of 16 samples was constructed using multilevel multifactor design [12] (Table 1).

\section{Calibration procedures}

The purpose of multivariate methods is to build a calibration model between the concentration of the analytes under study and the experimental data (absorbance in our case). The first step in model building involves constructing the calibration matrix for the quaternary mixture. In this study calibration set was optimized with the aid of the four level four factor design [12] resulting in 16 sample mixtures. Table 1 shows the composition of the 16 sample mixtures. The concentration of the four analytes in those 16 samples was chosen according to the calibration range of each drug and their ratio in dosage form. Another six validation mixtures (validation set) were prepared to measure the predictive power of the proposed models (Table 2).<smiles>CN(C)CCOC(c1ccccc1)c1ccccc1</smiles>

Diphenhydramine $\mathrm{HCl}$

. $\mathrm{HCl}$<smiles>COc1ccccc1OCC(O)CO</smiles>

Guaifenesin

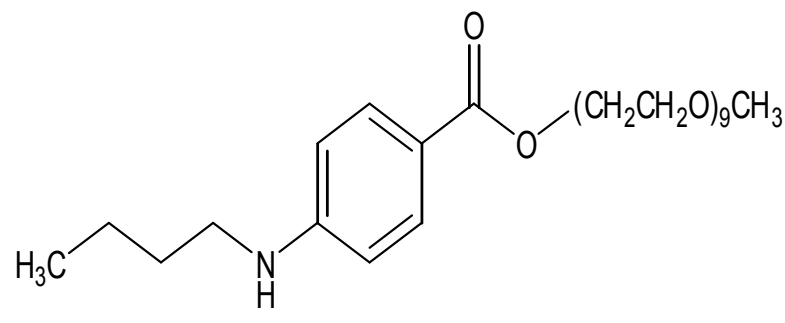

Benzonatate<smiles>CNC[C@@H](O)c1cccc(O)c1</smiles>

Phenyl ephrine $\mathrm{HCl}$

Figure 1: Chemical structures of four components of Bronchofree capsule 


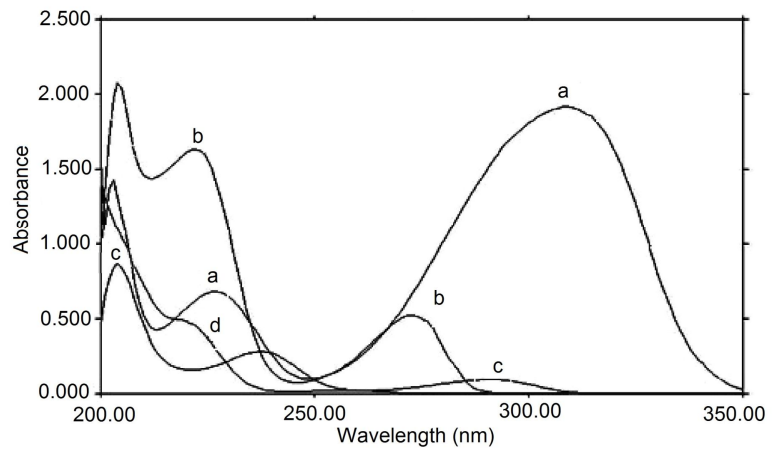

Figure 2: UV absorption spectra of $60 \mu \mathrm{mL}^{-1}$ of $\mathrm{BN}$ (a), $60 \mu \mathrm{gL} \mathrm{m}^{-1}$ of $\mathrm{GU}(\mathrm{b}), 6 \mu \mathrm{gL}^{-1}$ of $\mathrm{PH}$ (c) and 15 $\mu \mathrm{g} \mathrm{mL}^{-1}$ of DP (d)

Table 1: The four level four factor experimental design of the calibration set mixtures shown as concentrations of the mixture components in $\mathrm{gg} \mathrm{mL}^{-1}$

\begin{tabular}{lcccc}
\hline Mix. no. & DP & BN & GU & PH \\
\hline 1 & 10 & 40 & 40 & 4.8 \\
2 & 10 & 45 & 45 & 7.2 \\
3 & 11.25 & 45 & 60 & 5.4 \\
4 & 11.25 & 60 & 45 & 4.8 \\
5 & 15 & 45 & 40 & 6.6 \\
6 & 11.25 & 40 & 55 & 6.6 \\
7 & 10 & 55 & 55 & 5.4 \\
8 & 13.75 & 55 & 45 & 6.6 \\
9 & 13.75 & 45 & 55 & 4.8 \\
10 & 11.25 & 55 & 40 & 7.2 \\
11 & 13.75 & 40 & 60 & 7.2 \\
12 & 10 & 60 & 60 & 6.6 \\
13 & 15 & 60 & 55 & 7.2 \\
14 & 15 & 55 & 60 & 4.8 \\
15 & 13.75 & 60 & 40 & 5.4 \\
16 & 15 & 40 & 45 & 5.4 \\
\hline
\end{tabular}

\section{ANN results}

The ANN consists of three layers; two layers with connections to the outside world (an input layer where data are presented to the network and an output layer which holds the network response to given inputs) and one hidden layer (optimized afterwards). Since the large number of nodes in the input layer of the network (i.e. the number of wavelength readings for each solution) increases the CPU time for ANN modeling, the absorbance matrix was factor analyzed before introducing into the network using PCA and ANN model was run. For DP, PC-ANN failed to find relationship between the input nodes (PCs) and output nodes (concentrations) so inputs were raw data (wavelengths absorbances instead of PCs). There are 4 inputs for $\mathrm{BN}, \mathrm{GU}$ and $\mathrm{PH}$ (representing 4 PCs) while inputs for DP were 50 (absorbances at $231-280 \mathrm{~nm}$ ). This may be due to lack of characteristic features in DP spectrum, so all wavelengths should be included in the model. The output layer is the concentration matrix of four components. The hidden layer consists of just single layer which has been considered sufficient to solve similar or more complex problems. Moreover, more hidden layers may cause over-fitting [5]. Therefore, we used in our work two ANNs, one for prediction of $\mathrm{BN}, \mathrm{GU}$ and $\mathrm{PH}$ concentrations and other ANN for DP concentration prediction. The architectures of the two ANNs are shown in Figure 3. For proper modeling of ANN, different parameters should be optimized. These parameters are HNN, Lc, Lcd and Lci. Plackett Burman design was used for optimization of these parameters. The values of the parameters for each component are shown in Table 3. After optimization of parameters and architectures of the two ANNs, the training step proceeds. The trained ANNs were used for prediction of the concentrations of the four components in the validation set. The results are shown in Table 2.

\section{CRACLS}

The calibration set spectra were handled using a home-made CRACLS function (written as a code in the matlab program), in which each drug concentration was only used in modeling and

Table 2: Concentrations and percent recoveries of four components used in the validation set

\begin{tabular}{|c|c|c|c|c|c|c|c|c|c|c|c|c|}
\hline \multirow{2}{*}{$\begin{array}{l}\text { Mix. } \\
\text { no. }\end{array}$} & \multicolumn{4}{|c|}{$\begin{array}{l}\text { Mix. composition } \\
\left(\mu \mathrm{gL}^{-1}\right)\end{array}$} & \multicolumn{4}{|c|}{$\begin{array}{c}\mathrm{R} \% \\
\text { NN method } \\
\end{array}$} & \multicolumn{4}{|c|}{$\begin{array}{c}\text { R\% } \\
\text { CRACLS method }\end{array}$} \\
\hline & DP & BN & GU & $\mathrm{PH}$ & DP & BN & GU & PH & DP & BN & GU & PH \\
\hline 1 & 15 & 60 & 60 & 6 & 98.33 & 98.45 & 99.07 & 98.78 & 97.81 & 98.15 & 102.47 & 99.34 \\
\hline 2 & 12.5 & 40 & 40 & 7.2 & 98.00 & 101.94 & 101.32 & 98.57 & 100.85 & 102.34 & 98.71 & 100.28 \\
\hline 3 & 12.5 & 40 & 45 & 6.6 & 101.28 & 100.44 & 99.58 & & & & & 102.71 \\
\hline 4 & 15 & 60 & 45 & 7.2 & 102.33 & 101.25 & 99.92 & & & 100.71 & 101.66 & 98.83 \\
\hline 5 & 15 & 40 & 40 & 6.6 & 97.33 & 97.75 & 102.98 & 98. & 99.91 & 97.90 & 97.75 & 101.69 \\
\hline \multirow[t]{4}{*}{6} & 12.5 & 50 & 50 & 6 & 102.40 & 99.77 & 102.23 & 99.00 & 99.89 & 99.13 & 102.42 & 100.32 \\
\hline & \multirow{3}{*}{\multicolumn{3}{|c|}{$\begin{array}{c}\text { Mean } \\
\text { S.D } \\
\text { RMSEP }\end{array}$}} & & 99.95 & 99.94 & 100.85 & 98.98 & 100.35 & 99.89 & 100.19 & 100.53 \\
\hline & & & & & 2.311 & 1.613 & 1.570 & 0.643 & 2.308 & 1.776 & 2.223 & 1.449 \\
\hline & & & & & 0.2953 & 0.6933 & 0.6405 & 0.0780 & 0.2778 & 0.7510 & 1.0004 & 0.0947 \\
\hline
\end{tabular}


other drugs were considered to be an unknown interference. Two augmentations were found to be necessary to yield an acceptable model for all the components except for DP we need six augmentations. This choice was decided through the calculation of RMSEP values during prediction of the validation samples. The first augmentation showed RMSEP values of 2.144, 4.05 and 0.692 for $\mathrm{BN}, \mathrm{GU}$ and $\mathrm{PH}$ respectively and these values decreased in the next augmentation to be $0.751,1.0004$ and 0.0947 for the three components respectively. Further augmentations did not show statistically better RMSEP values, which indicated that more augmentations would not be beneficial. For DP, RMSEP value of the first augmentation was 5.813 and decreased gradually to 0.2779 in the sixth augmentation.

The values of RMSEP versus augmentation number for $\mathrm{PH}$ and DP were shown in Figure 4 $(\mathrm{PH}$ as a representative for $\mathrm{BN}$ and $\mathrm{GU})$. The CRACLS model was applied to predict the concentrations of the four components in the validation set, with the results, expressed as percentage recoveries, mean recovery, standard deviation (S.D) of recoveries and RMSEP are collected in table (2). Results were satisfactory and the recoveries were reasonable and the

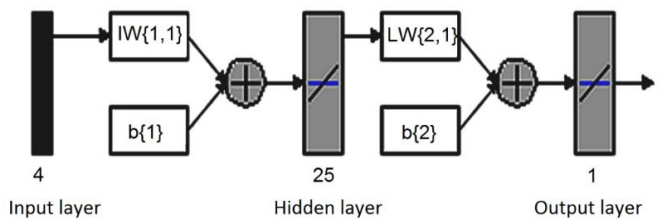

(a) method looks precise. Also the qualitative property of the CRACLS model was used to insure that there is no degradation occurs to BN in alkaline medium under experimental conditions. This is done by comparing the real spectrum of $\mathrm{BN}$ in distilled water and the predicted one by the CRACLS model in alkaline medium as shown in Figure 5.

\section{Application to pharmaceutical preparation}

The proposed models were used for the analysis of pharmaceutical preparation containing the four analytes. The results are shown in table 4 . Each value indicated is the mean of 3 determination of the same commercial batch. The results obtained from the analysis of pure powders of the analytes in presence and absence of pharmaceutical excipients added by the manufacturer (polypropylene glycol and polyethylene glycol) are indicated in Table 5. The results obtained were compared for the mean and the standard deviation using the $\mathrm{t}$ - test and $\mathrm{F}$ - test, respectively. There were no significant differences. In addition, the results found were in good agreement with the data indicated in the formulation given by the manufacturer.

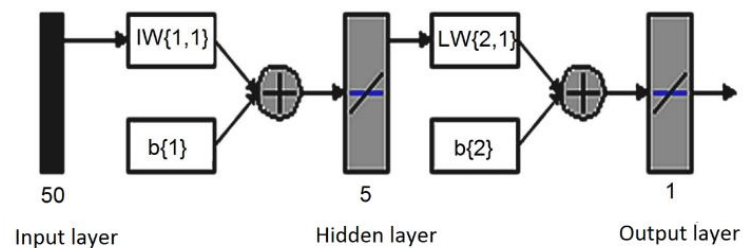

(b)

Figure 3: Different layers of the networks used for prediction of BN, GU and $\mathrm{PH}(\mathrm{a})$ and DP concentrations (b)

Table 3: Optimized parameters of ANNs

\begin{tabular}{lcccc}
\hline Drug & $\begin{array}{c}\text { Hidden neurons } \\
\text { number }\end{array}$ & $\begin{array}{c}\text { Learning } \\
\text { coefficient }\end{array}$ & $\begin{array}{c}\text { Learning coefficient } \\
\text { decrease }\end{array}$ & $\begin{array}{c}\text { Learning coefficient } \\
\text { increase }\end{array}$ \\
\hline DP & 5 & 0.001 & 1 & 100 \\
BN & 25 & 0.001 & 0.001 & 100 \\
GU & 25 & 0.001 & 0.001 & 100 \\
PH & 25 & 0.001 & 0.001 & 100 \\
\hline
\end{tabular}

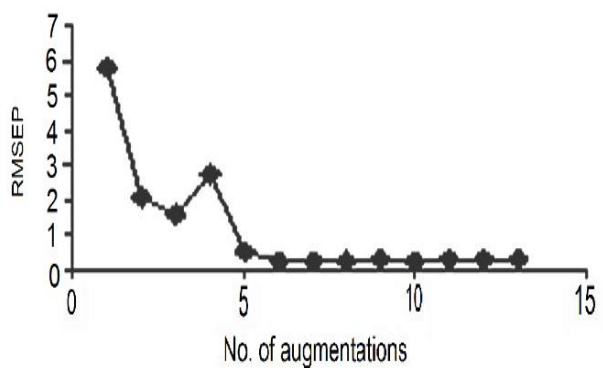

(a) set with different number of augmentations

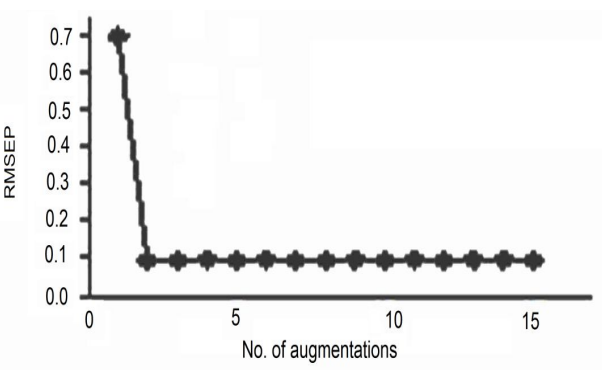

(b)

(b) concentrations in validation 


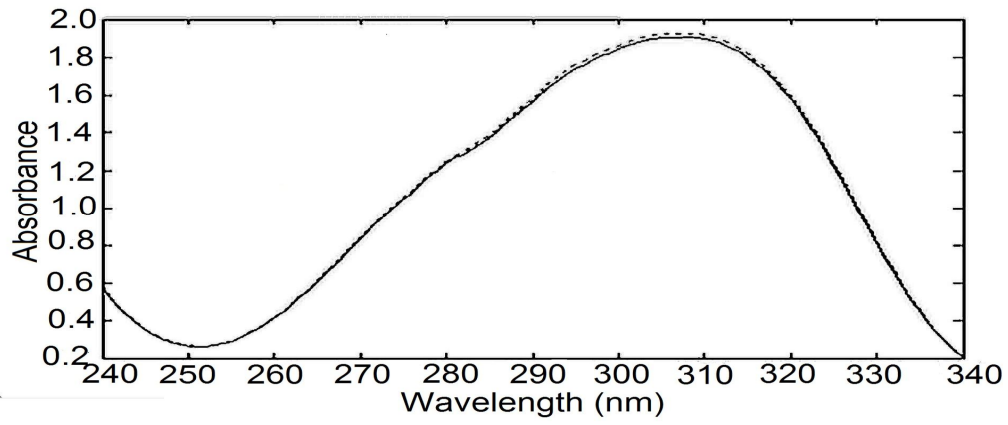

Figure 5: The spectrum of BN $\left(60 \mathrm{ug} \mathrm{mL}{ }^{-1}\right)$, the actual one in distilled water (__ _ $)$ and the predicted one by CRACLS method in alkaline medium $(\ldots \ldots \ldots)$

Table 4: Composition of Bronchofree Capsules (batch number 811062) as determined by the proposed methods

\begin{tabular}{|c|c|c|c|c|c|c|c|c|}
\hline \multirow[b]{2}{*}{$\begin{array}{l}\text { Sample } \\
\text { no. }\end{array}$} & \multicolumn{4}{|c|}{ ANN method } & \multicolumn{4}{|c|}{ CRACLS method } \\
\hline & DP R\% & BN R\% & GU R\% & PH R\% & DP R\% & BN R\% & GU R\% & PH R \% \\
\hline $\begin{array}{l}1 \\
2\end{array}$ & $\begin{array}{l}101.52 \\
102.40\end{array}$ & $\begin{array}{c}100.20 \\
98.76\end{array}$ & $\begin{array}{l}98.92 \\
98.90\end{array}$ & $\begin{array}{l}99.85 \\
97.50\end{array}$ & $\begin{array}{c}100.83 \\
98.17\end{array}$ & $\begin{array}{c}100.18 \\
99.24\end{array}$ & $\begin{array}{l}97.13 \\
99.21\end{array}$ & $\begin{array}{l}97.55 \\
97.52\end{array}$ \\
\hline 3 & 104.00 & 100.73 & 102.05 & 99.33 & 102.50 & 100.07 & 97.22 & 97.46 \\
\hline 4 & 100.90 & 101.52 & 97.37 & 97.33 & 97.86 & 100.77 & 99.94 & 99.43 \\
\hline $\begin{array}{l}\text { Mean } \\
\text { S.D. } \\
\text { RMSEP }\end{array}$ & $\begin{array}{c}102.21 \\
1.346 \\
0.3302\end{array}$ & $\begin{array}{c}100.30 \\
1.166 \\
0.5846\end{array}$ & $\begin{array}{c}99.31 \\
1.966 \\
1.0339\end{array}$ & $\begin{array}{c}98.50 \\
1.274 \\
0.1082\end{array}$ & $\begin{array}{c}99.84 \\
2.221 \\
0.2441\end{array}$ & $\begin{array}{c}100.07 \\
0.630 \\
0.2974\end{array}$ & $\begin{array}{c}98.37 \\
1.421 \\
0.9870\end{array}$ & $\begin{array}{c}97.99 \\
0.963 \\
0.1088\end{array}$ \\
\hline
\end{tabular}

*Each value is the mean of 3 determinations

Table 5: Statistical data of four components of Bronchofree Capsules in presence and absence of pharmaceutical excipients by proposed methods

\begin{tabular}{|c|c|c|c|c|c|c|c|c|}
\hline \multirow{2}{*}{$\begin{array}{l}\text { Sample } \\
\text { no. }\end{array}$} & \multicolumn{2}{|c|}{ DP R \% } & \multicolumn{2}{|c|}{ BN R\% } & \multicolumn{2}{|c|}{ GU R\% } & \multicolumn{2}{|c|}{ PH R\% } \\
\hline & Absence & Presence & Absence & Presence & Absence & Presence & Absence & Presence \\
\hline \multicolumn{9}{|l|}{$\mathbf{A N N}$} \\
\hline 1 & 98.70 & 102.00 & 98.55 & 99.28 & 99.63 & 101.19 & 99.93 & 102.38 \\
\hline 2 & 99.63 & 101.12 & 98.33 & 99.58 & 100.31 & 100.13 & 97.40 & 102.74 \\
\hline 3 & 101.73 & 100.33 & 98.75 & 98.37 & 100.42 & 101.10 & 100.73 & 99.18 \\
\hline Mean & 100.02 & 101.15 & 98.54 & 99.08 & 100.12 & 100.81 & 99.35 & 101.43 \\
\hline S.D. & 1.554 & 0.834 & 0.208 & 0.633 & 0.430 & 0.585 & 1.737 & 1.959 \\
\hline \multicolumn{9}{|c|}{ CRACLS } \\
\hline 1 & 102.90 & 101.00 & 100.52 & 100.77 & 98.05 & 99.10 & 99.58 & 99.76 \\
\hline 2 & 97.33 & 98.92 & 100.95 & 100.89 & 100.26 & 100.13 & 98.98 & 100.64 \\
\hline 3 & 102.27 & 102.60 & 99.74 & 99.52 & 100.68 & 102.4 & 99.14 & 101.31 \\
\hline Mean & 100.84 & 100.84 & 100.40 & 100.39 & 99.66 & 100.55 & 99.23 & 100.57 \\
\hline SD & 3.049 & 1.847 & 0.612 & 0.762 & 1.413 & 1.697 & 0.313 & 0.776 \\
\hline
\end{tabular}

\section{DISCUSSION}

In general, the goals of this paper are to present ANNs and CRACLS as attractive candidates for usual multivariate calibration using UV spectral data and to highlight the inherent characteristics of each method. The higher the number of the components in a mixture the more difficult the analysis and the lower the ability of traditional approaches of handling UV spectroscopic techniques to find robust and precise solutions. The ANN can handle linear and non linear data. The type of ANN used in this paper is the feed- forward model which is trained with the back propagation of errors learning algorithm.

For proper modelling of ANN, different parameters should be optimized. From the most important parameters that should be optimized carefully; the transfer function pair. Choice of transfer function depends on the nature of data you work on. Transfer function pair found to give best results in our work is purelin - purelin between input and hidden layer; and between hidden layer and outer layer. This is logic because the relationship between absorbance and concentration in our work is linear 
relationship. After optimization of parameters and architectures of the ANNs, we trained ANNs by different training functions and there was no difference in performance (i.e. there was no decrease in root mean square error of prediction (RMSEP)). Levenberg-Marquardt training algorithm (TRAINLM) was thus preferred as it is time saving. To avoid over fitting of our model, a validation set of six different samples was encountered in training step and ANN stops when RMSEP of calibration set decreased and that of validation set increased.

Melgaard et al [11] introduced CRACLS algorithm that can update the model during prediction without recalibration. The CRACLS algorithm is based on CLS so it retains the qualitative benefits of CLS, and the flexibility of PCR and PLS modeling when spectrally active components are not included in the calibration. Its high qualitative power allowed us to generate estimated pure-component spectra of $\mathrm{BN}$ to ensure its stability under the experimental conditions (alkaline medium). Finding the correct number of augmentations in CRACLS is less critical than choosing the optimal number of LVs in PLS [11]. The number of augmentations was selected through the calculation of RMSEP values during prediction of the validation samples.

\section{CONCLUSION}

The developed ANNS and CRACLS can be classified among selective and sensitive procedures and simpler and cost - effective than the reported HPLC method. These merits suggest the use of the proposed methods in quality control analysis of this quaternary mixture without interference of commonly encountered additives. Furthermore, the results in this paper give hopes for the use of smart chemometric approaches for the analysis of pharmaceutical products using cheap and simple instruments such as UV spectrophotometer even if the number of active constituents is high and the spectra are highly overlapped.

\section{ACKNOWLEDGEMENT}

The authors would like to extend their sincere appreciation to the Deanship of Scientific Research at King Saud University for funding this research through Research Group Project no. RGP - VPP - 322.

\section{REFERENCES}

1. Kishk SM, Salama I, Mostafa S, El-Sadek M. Stability indicating chromatographic method for the determination of benzonatate, diphenhydramine, guaifenesin and phenylephrine. J Liq Chromatogr Relat Technol. 2014; 37(5):726-747.

2. Budavari S, O'Neal M, Smith A, Heckelman P,Kinneary J. The Merck Index. An Encyclopedia of Chemicals, Drugs, and Biologicals. 12th edn. Whitehouse Station, NJ: Merck \& Co. Inc; 1996.

3. Goodman - Hillman A, Rall T, Nier A, Taylor $P$, editors. The Pharmacological Basis of Therapeutics. New York: McGraw Hill; 1996.

4. Sweetman SC. Martindale - The Complete Drug Reference. 36 ed. London, UK: The Pharmaceutical Press; 2009.

5. Khanchi AR, Mahani MK, Hajihosseini M, Maragheh MG , Chaloosi M , Bani F. Simultaneous spectrophotometric determination of caffeine and theobromine in Iranian tea by artificial neural networks and its comparison with PLS. Food chem. 2007 ;103(3): 1062- 68.

6. Darwish HW. Application of smart spectrophotometric methods and artificial neural network for the simultaneous quantitation of olmesartan medoxamil , amlodipine besylate and hydrochlorothiazide in their combined pharmaceutical dosage form. Chem Cent J. 2013; 7(22: 1- 9.

7. Darwish HW, Attia MI, Abdelhameed AS, Alanazi AM, Bakheit AH. Comparative ANNs with Different Input Layers and GA - PLS Study for Simultaneous Spectrofluorimetric Determination of Melatonin and Pyridoxine $\mathrm{HCl}$ in the Presence of Melatonin's Main Impurity. Molecules 2013; 18(1): 974-996.

8. Abbaspour A, Baramakeh L. Application of principle component analysis-artificial neural network for simultaneous determination of zirconium and hafnium in real samples. Spectrochim Acta A Mol Biomol Spectrosc. 2006; 64(2): 477-482.

9. Narváez - Rivas M, Gallardo E, Jurado J, Viera - Alcaide I, Pablos F, León - Camacho M. Application of artificial neural networks to determine the authentication of fattening diets of Iberian pigs according to their triacylglycerol profiles. Grasas $Y$ Aceites 2013; 64(2): 127-137.

10. loele $G$, De Luca $M$, Dinç $E$, Oliverio $F$, Ragno $G$. Artificial Neural Network Combined with Principal Component Analysis for Resolution of Complex Pharmaceutical Formulations. Chem Pharm Bull 2011; 59(1): 35-40.

11. Haaland DM, Melgaard DK. New augmented classical least squares methods for improved quantitative spectral analyses. Vibr Spectrosc. 2002; 29(1): 171 75.

12. Brereton RG. Multilevel Multifactor Designs for Multivariate Calibration. Analyst 1997; 122(12): 1521 1529.

Trop J Pharm Res, December 2014; 13(12): 2089 
13. Moffat AC, Osselton DM, Widdop B. Clarke's analysis of drugs and poisons: in pharmaceuticals, body fluids, and postmortem material. 3 ed: Pharmaceutical press; 2004.
14. Lin $W-J$, Chen $Y-Y$, Chen RR - L. Degradation kinetics of benzonatate in aqueous solutions. Int $J$ Pharm 1999; 176(2): 179-186.

15. Spiegel M, Stephens L. Schaum's Outline of Theory and Problems of Statistics. Schaum's Outline Series, 1999: McGraw Hill, New York. 